\title{
Effect of Prior Learning Method on Nursing Students' Practical Capacity
}

\author{
Shinhong Min, Soonyoung Yun
}

\begin{abstract}
We looked at how the practical capacity of nursing students was affected by the application of the Prior Learning Method in the fundamentals of nursing practice course. In order to compare practical capacity, self-efficacy, self-directed learning ability, and learning satisfaction were set as variables and results were calculated using SPSS 18.0. Comparing results after applying the Prior Learning Method to only the experimental group by classifying it as a group of experimental and control group, the results showed that self-efficacy in the experimental group was increased and learning satisfaction was high. There was a meaningful result of applying the Priority Learning Method to the demanding practical class, gaining satisfaction, and increasing confidence. It is necessary to verify it through repeated research and develop it into a better teaching method.
\end{abstract}

Keywords : Learning satisfaction, Self-directed learning ability, Self-efficacy

\section{INTRODUCTION}

The goal of nursing education in our country is to produce competent nurses with knowledge, skills and critical thinking skills, and students should develop knowledge-based practical skills through hands-on training [1]. Recent clinical practice sites have seen many fewer opportunities for students to experience clinical periods on-site due to the increasing demand for patient safety and rights protection. In the past, students have also experienced practical experience and clinical skills, but nowadays it is impossible.

Therefore, in the clinical practice, it is necessary to observe the work done by the senior nurses and to raise the critical thinking level accordingly. As a result, new caregivers' skills and lack of adaptability are becoming problems in the clinical scene, and the importance of hands-on education in universities is increasing [2]. In keeping with its importance, the University has created a situation similar to the actual situation, strengthening simulation facilities for training in it, and training related to it. For him, he is also strengthening the basic lessons that have to be equipped with the knowledge and skills of each technique to adapt to the actual situation. Students who were taking liberal arts-oriented classes in the previous semester are highly likely to experience many negative feelings such as pressure, anxiety, fear, tension, and anxiety as they engage in a major course exercise [3] and their confidence in the work.

A fundamental of nursing practice is the first subject to be

Revised Manuscript Received on July 22, 2019.

Shinhong Min*, Department of Nursing, Baekseok University, Cheonan, South Korea.shmin@bu.ac.kr

Soonyoung Yun, Department of Nursing, Baekseok University, Cheonan, South Korea. syb3000@bu.ac.kr completed in a nursing major, systematically teaching the theory and practice of applying basic nursing principles to clinical practice [4]. It is not only a theoretical basis for major courses but also an important subject for cultivating practical skills. In order to become a well-grounded nursing activity that has recently been emphasized, the theoretical basis must be firmly established. So many schools emphasize both the theory and practice of basic nursing and spend a lot of time. Basic nursing skills learned in the basic nursing practice are real skills to handle in practice, so confidence in behavior is the result of good performance [5]. Although it is a practice situation and a virtual situation, you need to be confident that you can learn practical skills in the situation and make it with confidence.

Having confidence in their practical performance can provide students facing clinical practice with an incentive to actively engage in hands-on practices as well as to reduce their fear of on-site practice. If nursing college students are not proficient enough in clinical skills in the school curriculum, they should be proficient in theory and practical knowledge in harmony with their lack of confidence when they are employed on the clinical scene as new caregivers, which in turn causes them to spend time and money on retraining and to consider leaving or transferring a nurse individually [6]. As such, self-efficacy and self-directed learning are variables related to the increasing importance of practical skills.

Self-efficacy refers to the degree of situational and concrete confidence in a person's belief that he or she can successfully perform an action to achieve a certain result [7]. The increased self-efficacy of nursing students will help them become more active in their hands-on practice, and will enable them to overcome numerous difficulties or conflicts in performing nursing as new caregivers after graduation [8] and make continued efforts to successfully carry out nursing.

On the other hand, self-directed learning ability refers to the ability of learners to take the lead in managing the learning process to ensure successful learning through systematic evaluation of results, and the benefits of self-directed learning enable students to acquire knowledge and continue education even in areas that do not affect school education [9]. Self-directed learning skills allow for continuous self-learning by selecting the knowledge and information you need and actively participating in learning on your own, enhancing autonomy and motivation for learning [10]. Also, students with self-directed learning skills during practical classes are full of motivation for learning, which improves satisfaction with the practice and sense of performance [11], which means the possibility of continuing

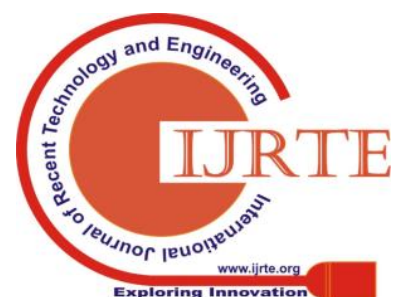


education in the clinical field due to their positive desire even undergraduate course.

Learning satisfaction refers to the degree of satisfaction with students' attitude, degree of preparation by professors, progress and content of lectures, and degree of study assessment [12]. Participating in self-directed classes after self-directed learning through prior practice will increase confidence and satisfaction with satisfaction with the classes. A thorough and effective exercise will give you confidence in basic care performance [13], and the more satisfied you are with the practice, the better your basic care skills can be [14]. When a nursing student enters a clinical practice with confidence and sufficient knowledge after a basic nursing practice, it is very effective in improving the clinical practice required as a nurse [15].

Therefore, we conducted this study to find out how the Priority Learning Method can play a leading role in honing knowledge and skills through self-directed learning and leading hands-on classes.

\section{MATERIALS AND METHODS}

\section{A. Research subjects}

The subjects of this study were selected as a sophomore majoring in nursing at B University located in C. Through the G-power program, the average difference verification of the two groups using t-test was applied to set the effect size to .65, the significant level to .05 , and the power to .80 . A total of 78 people were required for the study during bi-directional verification and 39 for each group. The subjects of this study were 42 experimenters, 41 control groups and 83 total participants, who met the number of samples, required for the study and understood the purpose of the study and agreed to participate in the study.

\section{B. Research design}

This study tried to verify the effects on self-efficacy, self-directed learning ability, and learning satisfaction by comparing the group of experiments that were taught by applying the design before and after the non-equivalence control.

\section{Research period}

The data collection was conducted on students who voluntarily agreed to participate in the study among those who took Fundamental nursing lessons from March 2 to June 15, 2018. The entire students were surveyed before the class, and the test group conducted a pre-learning method and then conducted survey. The number of students who agreed to this study was 42 each from the experimental group and the control group, but the number of samples used in the final analysis was 42 from the experimental group and 41 from the control group. The data collection was conducted twice in advance and after, explaining the purpose of the study before the beginning of the first class in order to collect the data, and indicating that the data collected were treated anonymously, separated from the consent form and questionnaires, and used only for research purposes. After obtaining consent for arbitrary research participation in writing, the contents of the after a nursing college student has graduated from the

questionnaire were explained and submitted by the government. Post-school material was collected after all classes were finished.

\section{Research hypothesis}

To achieve the purpose of this study, the following assumptions have been established:

First hypothesis: The experimental group that has been participated Prior Learning Method will have a higher self-efficacy score than the control group.

Second hypothesis: The experimental group that has been participated Prior Learning Method will have a higher self-directed learning ability score than a control group.

Third hypothesis: There will be differences in learning satisfaction scores between experimental and control groups.

\section{E. Research method}

Self-efficacy was measured by modifying the scale of 23 questions developed by Sherer [16]. A five-point recertification measure from "not at all" to "very much" means that the higher the score, the higher the self-efficacy.

Self-directed learning ability was measured using self-directed learning capacity tools developed by Lee[17]. The self-directed learning ability assessment questions consisted of a total of 45 questions, and detailed items consisted of learning plans (20 questions), learning practices (15 questions), and learning evaluations (10 questions). Each question was measured on a five-point Likert scale, and the higher the score, the higher the self-directed learning ability.

Learning satisfaction level was modified and used by the Learning Satisfaction Assessment Tool developed by Yoo [18]. Each question was measured from one point 'not at all' to five points 'definitely not' on a five-point Likert scale, and the higher the score, the higher the learning satisfaction level.

\section{F. Prior Learning Method}

Several students were selected from among those taking fundamental nursing classes. The students were asked to carry out pre-practices on the subject of next week's class. At this time, the students were given a general overview of the practical theme. The entire process was then trained after a preview of the course and precautions for the exercise. Then, students who had studied in the hands-on class had to demonstrate in advance and showed it to other students. Afterwards, the correct practical course was summarized and the precautions were highlighted. In addition, students who participated in the preceding exercise should be distributed to each team to lead the team members' practice. As a facilitator of the class, the professor played a role in compiling and arranging problems or modifications when they were made.

\section{G. Analysis of data}

For the purposes of this study, the data collected used the following methods of analysis using the SPSS18.0 Statistical Program.

First, the general characteristics of the experimental and control groups were obtained with mistakes and percentages, and homogeneity was analyzed using $\chi 2$-test and Fisher's exact test. 
Second, the self-efficacy and self-directed learning of the experimental and control groups were obtained with mean and standard deviation, and homogeneity was analyzed using the independent t-test.

Third, the difference between the average value of the experimental group and the control group for differences in pre-interference learning satisfaction and the difference between the two groups for post-interference learning satisfaction were analyzed using an input t-test.

\section{RESULTS AND DISCUSSION}

\section{A. Homogeneity test for general characteristics}

Homogeneity verification of the subject's general characteristics has shown that they are all homogeneous $\langle$ Table 1>.

Table 1: Homogeneity test for general characteristics

\begin{tabular}{|c|c|c|c|c|c|}
\hline \multirow[t]{2}{*}{ Variable } & \multirow[t]{2}{*}{$\begin{array}{c}\text { Categor } \\
\mathrm{y}\end{array}$} & $\begin{array}{c}\text { Experiment } \\
\text { al } \\
\text { group }(42)\end{array}$ & $\begin{array}{c}\text { Control } \\
\text { group(41) }\end{array}$ & \multirow[t]{2}{*}{$X^{2}$} & \multirow[t]{2}{*}{$\mathrm{p}$} \\
\hline & & $\mathrm{N}(\%)$ & $\mathrm{N}(\%)$ & & \\
\hline \multirow{2}{*}{ Sex } & Male & 6 & 8 & \multirow{2}{*}{0.404} & \multirow{2}{*}{0.525} \\
\hline & Female & 36 & 33 & & \\
\hline \multirow{2}{*}{ Religion } & Faithful & 26 & 25 & \multirow{2}{*}{0.008} & \multirow{2}{*}{0.931} \\
\hline & None & 16 & 16 & & \\
\hline \multirow{3}{*}{$\begin{array}{l}\text { One's } \\
\text { own } \\
\text { level of } \\
\text { study }\end{array}$} & High & 7 & 8 & \multirow{3}{*}{3.428} & \multirow{3}{*}{0.180} \\
\hline & Normal & 23 & 28 & & \\
\hline & Low & 12 & 5 & & \\
\hline \multirow{3}{*}{$\begin{array}{l}\text { A Study } \\
\text { on the } \\
\text { interest } \\
\text { in } \\
\text { Fundam } \\
\text { ental } \\
\text { Nursing } \\
\text { Practice } \\
\text { s } \\
\end{array}$} & $\begin{array}{l}\text { Satisfac } \\
\text { tion }\end{array}$ & 38 & 36 & \multirow{3}{*}{1.042} & \multirow{3}{*}{0.594} \\
\hline & Normal & 4 & 4 & & \\
\hline & $\begin{array}{l}\text { Unsatisf } \\
\text { actory }\end{array}$ & 0 & 1 & & \\
\hline
\end{tabular}

\section{B. Homogeneity test for Self-efficacy, self-directed learning}

The result of examining the subject's self-efficacy and prior homogeneity of self-directed learning is <Table 2$\rangle$. The self-efficacy of the experimental group was $65.28 \pm 7.95$ and the self-directed learning was $162.78 \pm 19.19$. The self-efficacy of the control group was 64.75 \pm 6.53 , self-directed learning was $158.97 \pm 11.90$. There was no significant difference between the experimental and control groups, indicating that they were homogeneous ( $p>.05)$.

Table 2: Homogeneity test for Self-efficacy, self-directed learning

\begin{tabular}{|l|c|c|c|c|}
\hline & $\begin{array}{c}\text { Experimental } \\
\text { group }\end{array}$ & Control group & \multirow{2}{*}{$\mathrm{t}$} & $\mathrm{p}$ \\
\cline { 2 - 3 } & $\mathrm{M} \pm \mathrm{SD}$ & $\mathrm{M} \pm \mathrm{SD}$ & & \\
\hline Self-efficacy & $65.28 \pm 7.95$ & $64.75 \pm 6.53$ & 0.331 & 0.742 \\
\hline $\begin{array}{l}\text { Self-directed } \\
\text { learning }\end{array}$ & $162.78 \pm 19.19$ & $158.97 \pm 11.90$ & 1.090 & 0.280 \\
\hline
\end{tabular}

\section{Hypothesis test 1}

First hypothesis is "The classed experimental group will have a higher self-efficacy score than the control group." The test group's self-efficacy score was $71.83 \pm 7.19$ points, up from the pre-inspection, while the control group was $64.65 \pm 8.50$ points, indicating a significant improvement in self-efficacy over the control group $(\mathrm{t}=-4.402, \mathrm{p}<0.001)$, which was supported $\langle$ Table 3$\rangle$.

Table 3: Hypothesis test 1

\begin{tabular}{|l|l|c|c|c|c|}
\hline \multirow{2}{*}{} & & $\begin{array}{c}\text { Pre- } \\
\text { examination }\end{array}$ & $\begin{array}{c}\text { Post- } \\
\text { examination }\end{array}$ & \multirow{2}{*}{$\mathrm{t}$} & $\mathrm{p}$ \\
\cline { 3 - 5 } & $\mathrm{M} \pm \mathrm{SD}$ & $\mathrm{M} \pm \mathrm{SD}$ & & \\
\hline \multirow{3}{*}{$\begin{array}{l}\text { Self- } \\
\text { efficacy }\end{array}$} & $\begin{array}{l}\text { Experimental } \\
\text { group }\end{array}$ & $\begin{array}{c}65.28 \pm \\
7.95\end{array}$ & $\begin{array}{c}71.83 \pm \\
7.19\end{array}$ & -4.402 & \multirow{2}{*}{0.000} \\
\cline { 2 - 6 } & $\begin{array}{l}\text { Control } \\
\text { group }\end{array}$ & $\begin{array}{c}64.75 \pm \\
6.53\end{array}$ & $\begin{array}{c}64.65 \pm \\
8.50\end{array}$ & 0.061 & \multirow{2}{*}{0.951} \\
\hline
\end{tabular}

\section{Hypothesis test 2}

Second hypothesis is "The classed experimental group will have a higher self-directed learning score than the control group." The self-directed learning score improved from $162.78 \pm 19.19$ to $166.66 \pm 17.96$ points, while the control group showed $158.97 \pm 11.90$ points in a preliminary survey and $158.68 \pm 16.80$ in a post-mortem survey, but the 'hypothesis 2 ' was rejected because it showed no statistically significant difference $\langle$ Table 4$\rangle$.

Table 4: Hypothesis test 2

\begin{tabular}{|l|l|c|c|c|c|}
\hline & & $\begin{array}{c}\text { Pre- } \\
\text { examinatio } \\
\mathrm{n}\end{array}$ & $\begin{array}{c}\text { Post- } \\
\text { examinatio } \\
\mathrm{n}\end{array}$ & \multirow{2}{*}{$\mathrm{t}$} & $\mathrm{p}$ \\
\cline { 3 - 4 } & $\mathrm{M} \pm \mathrm{SD}$ & $\mathrm{M} \pm \mathrm{SD}$ & & \\
\hline \multirow{2}{*}{$\begin{array}{l}\text { Self-dire } \\
\text { cted } \\
\text { learning }\end{array}$} & $\begin{array}{l}\text { Experiment } \\
\text { al group }\end{array}$ & $\begin{array}{c}162.78 \pm \\
19.19\end{array}$ & $\begin{array}{c}166.66 \pm \\
17.96\end{array}$ & -1.084 & \multirow{2}{*}{0.285} \\
\cline { 2 - 6 } & $\begin{array}{l}\text { Control } \\
\text { group }\end{array}$ & $\begin{array}{c}158.97 \pm \\
11.90\end{array}$ & $\begin{array}{c}158.68 \pm \\
16.80\end{array}$ & 0.087 & 0.931 \\
\hline
\end{tabular}

\section{E. Hypothesis test 3}

Third hypothesis is "There will be a difference between the learning satisfaction score of the experimental group and the control group that took the class." The study satisfaction level was $75.04 \pm 6.46$ points after the class, and the control group was $71.97 \pm 6$ points, which showed that the study satisfaction level was significantly higher than that of the control group, and "hypothesis 3 " was supported $(\mathrm{t}=2.083, \mathrm{p}=0.040)<$ Table $5>$.

Table 5: Hypothesis test 3

\begin{tabular}{|l|l|c|c|c|}
\hline & & Post-examination & \multirow{2}{*}{$\mathrm{t}$} & $\mathrm{p}$ \\
\cline { 3 - 3 } & & $\mathrm{M} \pm \mathrm{SD}$ & \multirow{2}{*}{2.083} & 0.040 \\
\hline $\begin{array}{l}\text { Learning } \\
\text { satisfactio } \\
\mathrm{n}\end{array}$ & $\begin{array}{l}\text { Experimental } \\
\text { group }\end{array}$ & $75.04 \pm 6.46$ & \\
\cline { 2 - 3 } & Control group & $71.97 \pm 6.96$ & \\
\hline
\end{tabular}

\section{CONCLUSION}

Students who have conducted prior study in this study have already been trained before the formal class, so they have shown an active attitude in the class without feeling confident and unwillingness to practice. In particular, there has been a significant increase in self-efficacy and satisfaction among students in the study group, which naturally allows them to learn more deeply as they serve to guide other fellow students in detail, such as an assistant in class. Teaching classmates is believed to have increased the

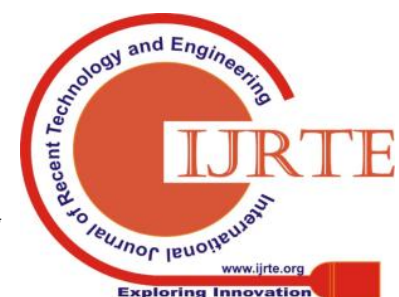


level of learning satisfaction and increased the level of self-efficacy. The results of self-directed learning showed that the comparison was not significant, and the analysis of the cause shows that the professor taught so much that he relied on prior learning and was considered passive as the professor intended.

As students choose the many skills that they want to do first among various kinds of skills, they are more interested in the practice, practice first, and teach their fellow students during regular classes, so they are more interested in the practice, gain satisfaction, and continue to be an inspiring teaching method as a professor as a result of increasing confidence. However, the challenge remains for professors to devote more time and effort to their students. In order to encourage students to learn more self-directly, the professor suggests ways to combine videos that are already available and to induce prior learning by acting as facilitators. Students will soon have to overcome the anxiety and fear of upcoming clinical practices, and the faculty will have to apply learner-oriented teaching methods to help students become competent nurses without being daunted in practice.

\section{ACKNOWLEDGMENT}

This research was supported by Baekseok University in Korea.

\section{REFERENCES}

1. S. H. Yang, J. H. Won, H. J. Baek, H. S. Jo, J. H. Gang, J. I. Lee, et al., Fundamentals of Nursing, Hyeonmunsa, 2018.

2. K. A. Song, H. S. Park, Y. H. Hong, K. I. Lee, S. K. Jeong, B. H. Jo, et al., Fundamentals of Nursing Intervention \& Skills, Sumunsa; 2017.

3. K. S. Han, J. Y. Cho, "A study on the experience of fundamental nursing practice", Journal of Korean Academy of Nursing, Vol.29(2), 1999, pp.293-303.

4. E. J. Yeun, "Effectiveness of Video-Record Method on Fundamental Nursing Skill Education - Focused on Intramuscular Injection Practice", The Journal of Korean academic society of nursing education, Vol. 5(1), 1999, pp.86-96

5. H. Y. Jeong, S. Kang, "The Influence of Recognition of Importance and Self-Directed Learning Ability on Confidence in Performance of Basic Nursing Skills among Nursing Students", Journal of digital convergence, Vol. 16(6), 2018, pp. 241-250. https://www.earticle.net /Article/A332831

6. C. Barret, F. Myrick, "Job satisfaction in preceptorship and its effect on the clinical performance of the preceptee", Journal of Advanced Nursing, Vol. 27, 1998, pp. 364-371.

7. R. S. Vealey, "Conceptualization of sport-confidence and competitive orientation: Preliminary investigation and instrument development", Journal of Sport Psychology, Vol. 8, 1986, pp. 221-246.

8. M. Y. Jo, "Effects of Core Fundamental Nursing Skills Education on Self-efficacy, Clinical Competence and Practice Satisfaction in Nursing Students", J Korean Acad Fundam Nurs, Vol. 21(3), 2014, pp. 292-301.

9. H. W. Jeon, "Interpretation of the meaning of self-directed learning", Research of Learner-Centered Curriculum and Instruction, Vol. 12(1), 2012, pp. 373-392. http://www.kalci.org/html /?pmode=searchh

10. Y. A. Kim, Y. H. Kim, "Factors Influencing Self-Directed Learning Ability in Beginning Nursing Students", Asia-pacific Journal of Multimedia Service Convergent with Art, Humanities and Sociology, Vol. 6(9), 2016, pp. 459-471. http://www.ndsl.kr/ndsl/search/detail/articlearticleSearchResultDetail.d $\mathrm{o} ? \mathrm{cn}=\mathrm{ART} 002146890$

11. Y. H. Kim, "Effects of utilizing animation prior to fundamental nursing practice on learning motivation and self-directedness in student nurses", The Korean Journal of Fundamentals of Nursing, Vol. 17(2), 2010, pp. 240-248.
12. M. R. Song, E. M. Kim, S. J. Yu, "Analysis on the Competency of Nursing Students' Basic Nursing Skills", The Korea Contents Society, Vol. 12(6), 2012, pp. 390-401.

13. S. O. Kim, S. H. Cho, "Learning Effectiveness according to the Practical Teaching Method, Self Confidence and Degree of Knowledge Achievement of Aseptic Technique by Nursing Students", The Korean Journal of Fundamentals of Nursing, Vol. 6(1), 1999, pp.7-17.

14. E. J. Shin, "A Study Related to Self-Efficacy, Satisfaction with Practice and Fundamentals of Nursing Practicum" The Korean Journal of Fundamentals of Nursing, Vol. 15(3), 2008, pp. 380-386.

15. B. H. Cho, M. H. Ko, S. Y. Kim, "Effectiveness of Web Based Learning on Competence, Knowledge, and Confidence in Foley-Catheter Management in Basic Nursing Education", The Korean Journal of Fundamentals of Nursing, Vol. 11(3), 2004, pp. 248-255.

16. M. Sherer, J. Maddux, B. Mercandante, S. Prentice-Dunn, B. Jacobs, "The Self-Efficacy Scale: Construction and Validation", Psychological Reports, Vol. 51, 1982, pp. 663-671.

17. S. J. Lee, A Study on the Development of Life-Skills: Communication, Problem Solving, and Self-Directed Learning. Seoul, Korean Educational development Institute, 2003.

18. M. S. Yu, "Development of standardized patient managed instruction for fundamentals of nursing course", unpublished, 2001. (Journal Online Sources style) K. Author. (year, month). Title. Journal [Type of medium]. Volume(issue), paging if given.

\section{AUTHORS PROFILE}

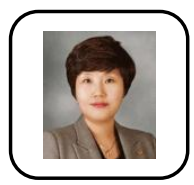

Shinhong Min, Ph.D., RN.

Associate Professor of Nursing at Baekseok University Education details: Adult healthy Nursing.

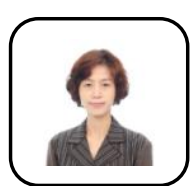

Soonyoung Yun, Ph.D., RN.

Associate Professor of Nursing at Baekseok University Editorial Committee of the Korean Convergence Society Education details: Fundamentals of nursing, emergency nursing 